\title{
Molecular Characterization of the Hemagglutinin and Neuraminidase Genes of H5N1 Influenza A Viruses Isolated from Poultry in Vietnam from 2004 to 2005
}

\author{
Yukiko MURAMOTO ${ }^{1,2,3)}$, Thi Quynh Mai LE ${ }^{4)}$, Lien Song PHUONG ${ }^{5}$, Tung NGUYEN ${ }^{5}$, Thu Ha NGUYEN ${ }^{5}$, \\ Yuko SAKAI-TAGAWA $A^{2,3)}$, Kiyoko IWATSUKI-HORIMOTO ${ }^{2,3)}$, Taisuke HORIMOTO ${ }^{2,3)}$, Hiroshi KIDA $^{6}$ and \\ Yoshihiro KAWAOKA ${ }^{1,2,3,7) *}$ \\ 1) International Research Center for Infectious Diseases, and ${ }^{2)}$ Division of Virology, Department of Microbiology and Immunology, \\ Institute of Medical Science, The University of Tokyo, Tokyo 108-8639, ${ }^{3)}$ Core Research for Evolutional Science and Technology, Japan \\ Science and Technology Agency, Saitama 332-0012, 6) Laboratory of Microbiology, Department of Disease Control, Graduate School of \\ Veterinary Medicine, Hokkaido University, Sapporo 060-0818, Japan, ${ }^{4)}$ National Institute of Hygiene and Epidemiology, Hanoi, \\ ${ }^{5)}$ National Center for Veterinary Diagnosis, Department of Animal Health, Ministry of Agriculture and Rural Development, Hanoi, \\ Vietnam and ${ }^{7)}$ Department of Pathobiological Sciences, School of Veterinary Medicine, University of Wisconsin-Madison, Madison, \\ Wisconsin 53706, U.S.A.
}

(Received 2 November 2005/Accepted 24 January 2006)

ABSTRACT. Highly pathogenic H5N1 avian influenza A viruses have been spreading among domestic poultry, wild aquatic birds, and humans in many Asian countries since 2003. The largest number of patients, to date, infected with the H5N1 viruses are in Vietnam, where these viruses continue to cause outbreaks in domestic poultry. Here, we molecularly characterized the hemagglutinin and neuraminidase genes of nine H5N1 viruses isolated between January 2004 and August 2005 from domestic poultry in Vietnam. We found that several groups of highly pathogenic H5N1 avian influenza viruses are circulating among these birds, which suggests that $\mathrm{H} 5 \mathrm{~N} 1$ viruses of different lineages have been introduced into Vietnam multiple times.

KEY WORDS: H5N1 avian influenza virus, hemagglutinin, neuraminidase.

J. Vet. Med. Sci. 68(5): 527-531, 2006

Influenza A viruses are enveloped viruses covered with surface glycoproteins, including two integral membrane proteins - hemagglutinin (HA), which possesses receptorbinding activity, and neuraminidase (NA), which possesses the sialidase activity required for the release of progeny viruses from the cell surface. Influenza A viruses are classified into subtypes based on their antigenic differences. To date 16 HA subtypes and 9 NA subtypes of viruses have been isolated from aquatic birds, the natural reservoir of influenza A viruses [16]. Among these subtypes are viruses belonging to the $\mathrm{H} 5$ or $\mathrm{H} 7$ subtype, which are highly pathogenic in domestic poultry.

In 1997, in Hong Kong, a pathogenic avian H5N1 influenza virus infected 18 people, 6 of whom died $[2,15]$. All of the viruses isolated from patients contained only avian virus genes and were not reassortants with human viruses [2, 15]. These infections were, therefore, recognized as the first cases of direct transmission of influenza viruses from avian species to humans with lethal outcome. Since late 2003, highly pathogenic H5N1 avian influenza viruses have spread among domestic poultry and wild aquatic birds in many Asian countries (World Organization for Animal Health [OIE] [http://www.oie.int]) [1, 7], devastating domestic poultry populations. As of November 29, 2005, more than 133 humans have been infected with these H5N1 viruses. The high mortality associated with these infections,

\footnotetext{
* Correspondence to: Kawaoka, Y., Division of Virology, Department of Microbiology and Immunology, Institute of Medical Science, University of Tokyo, Shirokanedai, Minato-ku, Tokyo 108-8639, Japan.
}

coupled with the difficulty in controlling these outbreaks, has raised concerns of a possible human pandemic. Vietnam has seen the largest number of patients infected with the H5N1 viruses: 93 patients, with 42 deaths (World Health Organization [WHO] [http://www.who.int/en/]). Outbreaks of the $\mathrm{H} 5 \mathrm{~N} 1$ virus continue to cause problems there. To better understand the $\mathrm{H} 5 \mathrm{~N} 1$ viruses circulating in domestic poultry populations in Vietnam, we molecularly characterized the HA and NA of viruses isolated between January 2004 and August 2005.

Tracheal swabs were collected from domestic poultry in different provinces in Vietnam from January 2004 to August 2005 (Table 1 and Fig. 1). Samples were inoculated into embryonated hen's eggs, and viral RNAs extracted from the virus-containing allantoic fluid by using a commercial kit (QIAamp Viral RNA mini kit, Qiagen, Hilden, Germany). HA and NA gene segments were amplified by RT-PCR using reverse transcriptase (SuperScript III Reverse Transcriptase, Invitrogen, CA, U.S.A.), DNA polymerase (PfuUltra High-Fidelity DNA Polymerase, Stratagene, CA, U.S.A.), and primers for the HA and NA genes of H5 viruses (available upon request). These PCR-derived dsDNAs were then cloned into a vector (TOPO vector, Invitrogen, CA, U.S.A.) and two or three clones of each isolate were sequenced with an ABI PRISM 3100 Genetic Analyzer (Applied Biosystems, CA, U.S.A.). All sequences were deposited in the Influenza Sequence Database (http:// daphne.lanl.gov/) [8]. Phylogenetic analysis (Fig. 2) was performed by using Clustal W program.

Sequence analysis of the HA genes from the nine isolates 
Table 1. H5N1 avian influenza viruses and the accession numbers of the HA and NA sequences analyzed in this study

\begin{tabular}{|c|c|c|c|c|c|}
\hline \multirow{2}{*}{ Virus } & \multirow{2}{*}{ Abbreviations } & \multirow{2}{*}{$\begin{array}{c}\text { Date of } \\
\text { sample } \\
\text { collection }\end{array}$} & \multirow{2}{*}{$\begin{array}{l}\text { Province of } \\
\text { sample } \\
\text { collection }\end{array}$} & \multicolumn{2}{|c|}{ Accession no. of gene } \\
\hline & & & & HA & NA \\
\hline $\mathrm{A} /$ chicken/Vietnam/G04/04 & CkG04 & Jan. 2004 & Hatay & ISDN128306 & ISDN128352 \\
\hline $\mathrm{A} /$ chicken/Vietnam/G62/05 & CkG62 & Jan. 2005 & Thaibinh & ISDN128307 & ISDN128353 \\
\hline $\mathrm{A} /$ duck/Vietnam/5001/05 & Dk5001 & Jan. 2005 & Hatay & ISDN128302 & ISDN128348 \\
\hline $\mathrm{A} / \mathrm{duck} /$ Vietnam/5003/05 & Dk5003 & Jan. 2005 & Angiang & ISDN128303 & ISDN128349 \\
\hline $\mathrm{A} /$ duck/Vietnam/5004/05 & Dk5004 & Jan. 2005 & Tiengiang & ISDN128304 & ISDN128350 \\
\hline $\mathrm{A} /$ chicken/Vietnam/TY9/05 & CkTY9 & Apr. 2005 & Hagiang & ISDN128308 & ISDN128354 \\
\hline $\mathrm{A} /$ duck/Vietnam/5082/05 & Dk5082 & Jun. 2005 & Thaibinh & ISDN128305 & ISDN128351 \\
\hline A/chicken/Vietnam/TY25/05 & CkTY25 & Jul. 2005 & Ninhbinh & ISDN128309 & ISDN128355 \\
\hline $\mathrm{A} /$ chicken/Vietnam/TY31/05 & CkTY31 & Aug. 2005 & Hatay & ISDN128310 & ISDN128356 \\
\hline
\end{tabular}

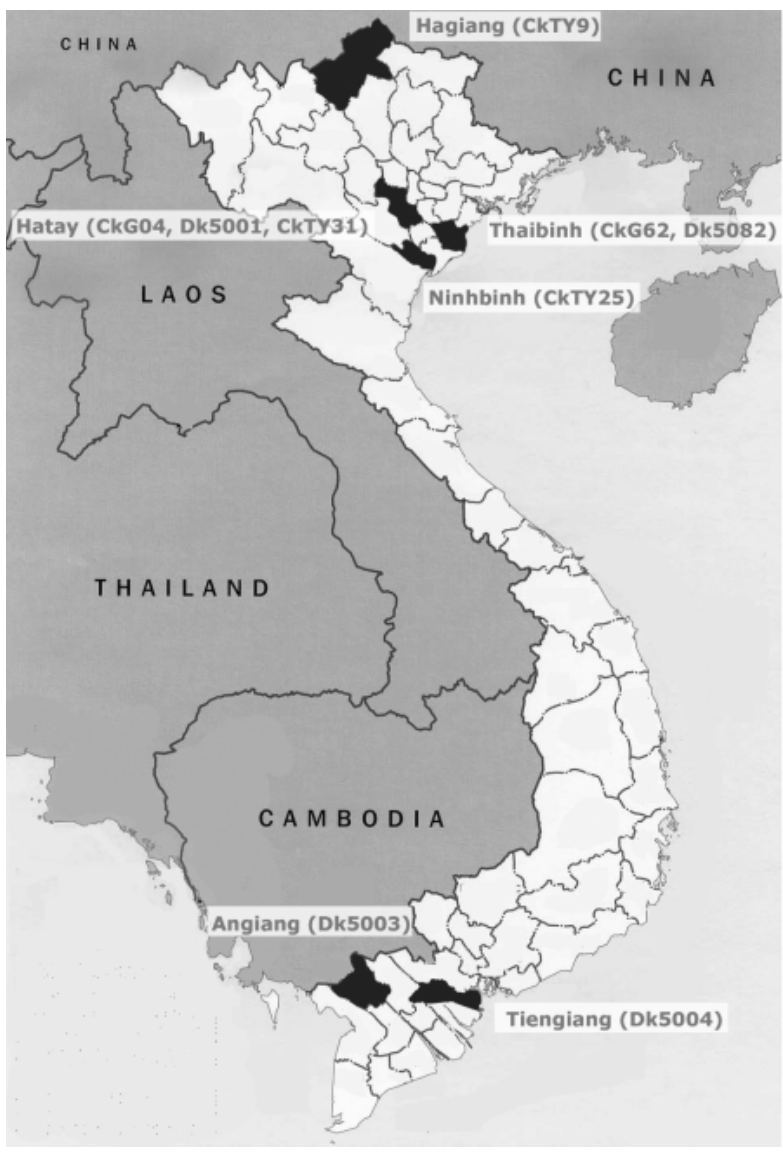

Fig. 1. Location of the Vietnamese provinces where avian H5N1 virus isolate samples were collected.

showed that all the HAs examined contained multiple basic amino acids at the cleavage site, although there were some variations (PQRERRRKKR/G, PQRERRKKR/G, and PQRERRRKR/G). Because HAs with multiple basic amino acids at their cleavage site are readily cleaved by ubiquitous cellular proteases $[5,14]$, these nine isolates are likely to be highly virulent to chickens.

The phylogenetic analysis of the HA genes showed that
H5N1 viruses isolated after 2003, including the nine Vietnamese isolates in this study, can be divided into three clades (Fig. 2A). Six of the Vietnamese isolates sequenced here are closely associated with the $\mathrm{H} 5 \mathrm{~N} 1$ viruses that have been isolated from poultry and humans in Vietnam since 2004 (clade 3). These viruses may, therefore, be enzootic in Vietnam. A/chicken/Vietnam/G62/05 isolated in early 2005 belongs to the first clade, and A/chicken/Vietnam/TY25/05 and A/chicken/Vietnam/TY31/05 isolated in July and August 2005, respectively, to the second clade. The viruses in clade 2 were isolated in several countries, including Japan, Korea, China, and Indonesia. While the NA genes of $\mathrm{H} 5 \mathrm{~N} 1$ viruses isolated after 2003 are divided into two clades, the phylogenetic relationship of the NAs of the nine Vietnamese isolates was essentially the same as that of their HA genes except A/chicken/Vietnam/G62/05 belongs to clade 2 (Fig. 2B).

The HAs of avian influenza viruses preferentially bind to receptors that terminate in an $\alpha(2,3)$-linked sialic acid, whereas those of human viruses preferentially bind to receptors terminating in an $\alpha(2,6)$-linked sialic acid $[11,13]$. In the past three pandemics, the receptor-binding specificity of the pandemic viruses converted from the avian virus-preferred $\alpha(2,3)$-linked sialic acid receptor to the human viruspreferred $\alpha(2,6)$-linkage [3,9]. Thus, for avian viruses to cause a pandemic among humans, the receptor-binding specificity of their HAs may have to change to $\alpha(2,6)$-linked sialic acid specificity. Here, alignment of the HA amino acid sequences revealed that all of the poultry isolates examined in this study possessed Gln at position 226 and Gly at position 228 (in $\mathrm{H} 3$ numbering), which are known to be associated with binding to $\alpha(2,3)$-linked sialic acids [12]. In addition, the other amino acids of the receptor-binding site (residues Tyr98, Ser136, Trp153, Ile155, His183, Asn186, Glu190, and Leu194) were identical among all nine isolates and to those of the HA of A/Hong Kong/156/97, an H5N1 virus isolated from a patient in Hong Kong in 1997 and known to preferentially bind to $\alpha(2,3)$-linked but not $\alpha(2,6)$ linked sialic acids $[4,10]$. These results suggest that the HAs of these nine isolates would preferentially recognize $\alpha(2,3)$-linked sialic acids. Thus, it is unlikely for these isolates to be efficiently transmitted among humans without 
A

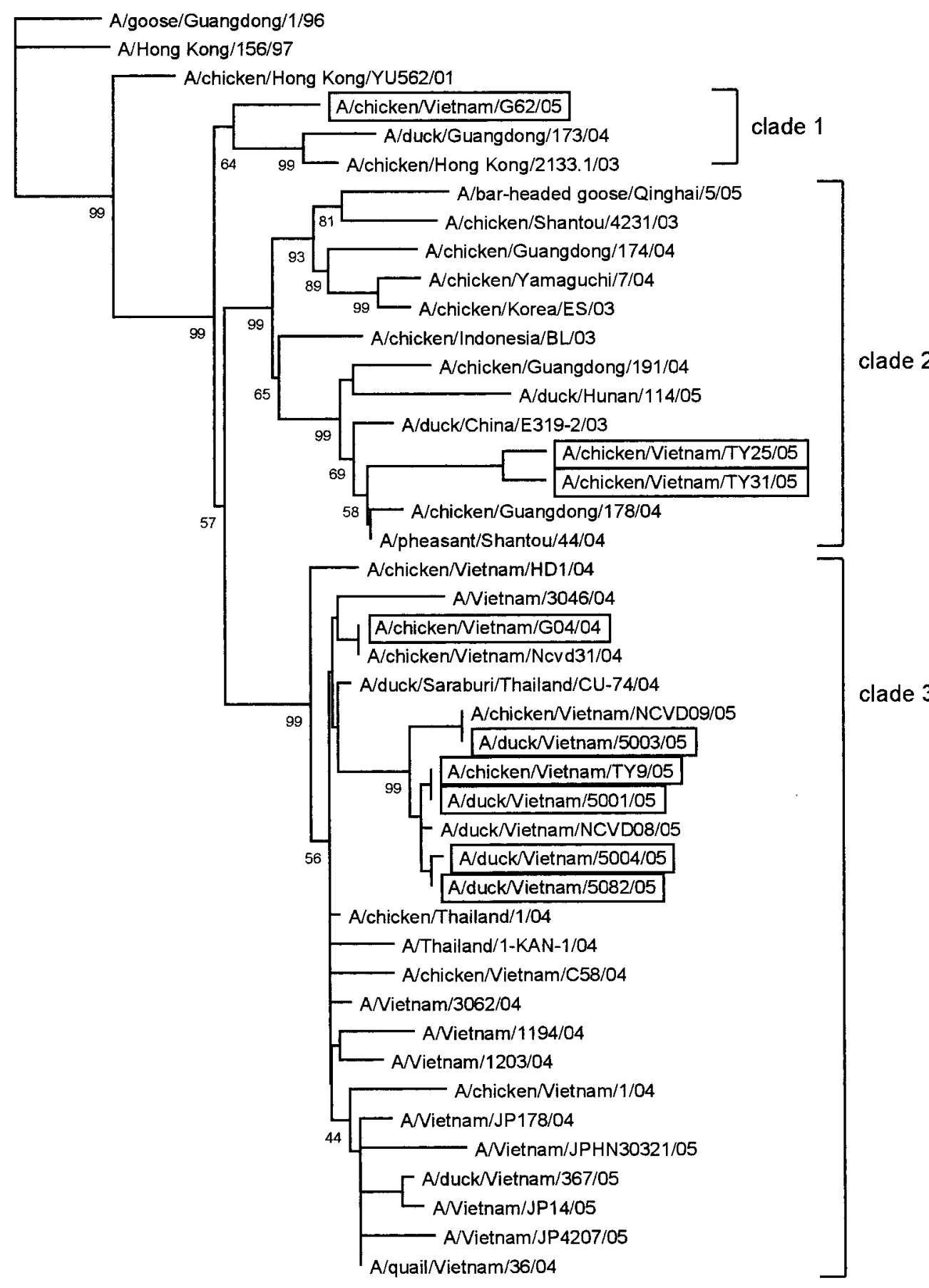

Fig. 2. The phylogenetic trees of the H5 HA (A) and N1 NA (B) genes of influenza A viruses. Viruses analyzed in this study are depicted in boxes. Phylogenetic trees were inferred from nucleotide sequences by the neighbor-joining method. Nucleotides 501-1735 (1235 bases) of the H5 HA genes and 441-1370 (930 bases) of the N1 NA genes were used for the phylogenetic analyses. The scale bar indicates 0.01 nucleotide changes per site. Numbers at the nodes indicate confidence levels of a bootstrap analysis with 1,000 replications as a percentage value. Only the bootstrap values that are critical for defining important groups are shown. 
B

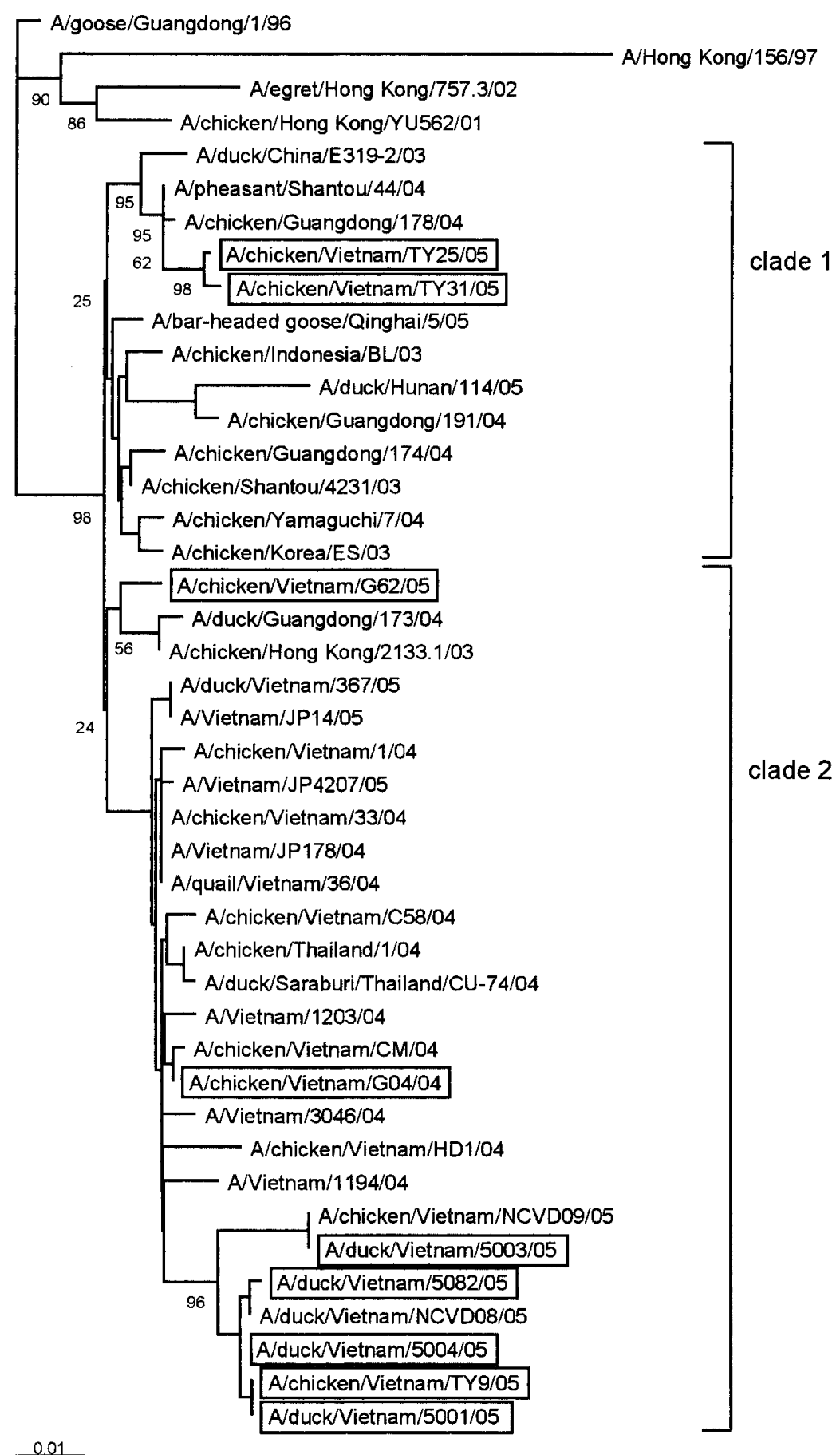

additional mutations that would make them recognize $\alpha(2,6)$-linked sialic acids.

Alignment of the NA amino acid sequences revealed that all nine isolates contain a 20-amino acid deletion in the stalk region. Such a deletion is associated with adaptation of influenza viruses from aquatic birds to chickens [10]. In fact, a similar deletion has been detected in other H5N1 viruses isolated since 2002 from land-based poultry in Viet- 
nam and other Asian countries [6] as well as in $\mathrm{H} 5 \mathrm{~N} 1$ viruses isolated in the 1997 outbreak in Hong Kong (e.g., A/ Hong Kong/156/97) [2]. Our findings, therefore, indicate that all of the isolates in our study have been adapted to land-based poultry such as chickens and quail.

Here, we have demonstrated that several groups of highly pathogenic $\mathrm{H} 5 \mathrm{~N} 1$ avian influenza viruses have been circulating among poultry in Vietnam, suggesting that $\mathrm{H} 5 \mathrm{~N} 1$ viruses of different lineages have been introduced into Vietnam multiple times. How these viruses were introduced into Vietnamese poultry remains unknown. Several possible routes exist, including introduction by wild birds, virus-contaminated materials, or imported poultry and ducks. Strict control of the introduction of potentially virus-contaminated materials into countries would help limit or prevent the establishment of these viruses in domestic birds; however, since the $\mathrm{H} 5 \mathrm{~N} 1$ virus is now part of the wild bird population $[1,7]$, the virus can also be introduced into domestic poultry by wild birds. Continued surveillance of poultry for influenza infection is critical to minimize the magnitude of an outbreak and thus limit the risk of human infection.

ACKNOWLEDGEMENTS. We thank Susan Watson and Krisna Wells for editing the manuscript and Yuko Kawaoka for the illustration. This work was supported by CREST (Japan Science and Technology Agency), and by grants-inaid from the Ministries of Education, Culture, Sports, Science, and Technology and of Health, Labor, and Welfare of Japan, and by National Institute of Allergy and Infectious Diseases Public Health Service research grants.

\section{REFERENCES}

1. Chen, H., Smith, G. J., Zhang, S. Y., Qin, K., Wang, J., Li, K. S., Webster, R. G., Peiris, J. S. and Guan, Y. 2005. Nature (Lond.) 436: 191-192.

2. Claas, E. C., Osterhaus, A. D., van Beek, R., De Jong, J. C.,
Rimmelzwaan, G. F., Senne, D. A., Krauss, S., Shortridge, K. F. and Webster, R. G. 1998. Lancet 351: 472-477.

3. Glaser, L., Stevens, J., Zamarin, D., Wilson, I. A., Garcia-Sastre, A., Tumpey, T. M., Basler, C. F., Taubenberger, J. K. and Palese, P. 2005. J. Virol. 79: 11533-11536.

4. Ha, Y., Stevens, D. J., Skehel, J. J. and Wiley, D. C. 2001. Proc. Natl. Acad. Sci. U.S.A. 98: 11181-11186.

5. Horimoto, T. and Kawaoka, Y. 1994. J. Virol. 68: 3120-3128.

6. Li, K. S., Guan, Y., Wang, J., Smith, G.. J., Xu, K. M., Duan, L., Rahardjo, A. P., Puthavathana, P., Buranathai, C., Nguyen, T. D., Estoepangestie, A. T., Chaisingh, A., Auewarakul, P., Long, H. T., Hanh, N. T., Webby, R. J., Poon, L. L., Chen, H., Shortridge, K. F., Yuen, K. Y., Webster, R. G. and Peiris, J. S. 2004. Nature (Lond.) 430: 209-213.

7. Liu, J., Xiao, H., Lei, F., Zhu, Q., Qin, K., Zhang, X. W., Zhang, X. L., Zhao, D., Wang, G., Feng, Y., Ma, J., Liu, W., Wang, J. and Gao, G. F. 2005. Science 309: 1206.

8. Macken, C., Lu, H., Goodman, J. and Boykin, L. 2001. pp. 103-106. In: Options for the Control of Influenza IV (Osterhaus, A.D.M.E. Cox, N. and Hampson, A.W. eds.), Elsevier Science, Amsterdam.

9. Matrosovich, M., Tuzikov, A., Bovin, N., Gambaryan, A., Klimov, A., Castrucci, M. R., Donatelli, I. and Kawaoka, Y. 2000. J. Virol. 74: 8502-8512.

10. Matrosovich, M., Zhou, N., Kawaoka, Y. and Webster, R. 1999. J. Virol. 73: 1146-1155.

11. Rogers, G.. N. and Paulson, J. C. 1983. Virology 127: 361-373.

12. Rogers, G. N., Paulson, J. C., Daniels, R. S., Skehel, J. J., Wilson, I. A. and Wiley, D. C. 1983. Nature (Lond.) 304: 76-78.

13. Rogers, G. N., Pritchett, T. J., Lane, J. L. and Paulson, J. C. 1983. Virology 131: 394-408.

14. Stieneke-Grober, A., Vey, M., Angliker, H., Shaw, E., Thomas, G., Roberts, C., Klenk, H. D. and Garten, W. 1992. EMBO J. 11: 2407-2414.

15. Subbarao, K., Klimov, A., Katz, J., Regnery, H., Lim, W., Hall, H., Perdue, M., Swayne, D., Bender, C., Huang, J., Hemphill, M., Rowe, T., Shaw, M., Xu, X., Fukuda, K. and Cox, N. 1998. Science 279: 393-396.

16. Webster, R. G., Bean, W. J., Gorman, O. T., Chambers, T. M. and Kawaoka, Y. 1992. Microbiol. Rev. 56: 152-179. 